\title{
Reversible (Patho)Physiologically Relevant Test Interventions: Rationale and Examples
}

\author{
Kathleen Cantow, Mechthild Ladwig-Wiegard, Bert Flemming, \\ Andrea Fekete, Adam Hosszu, and Erdmann Seeliger
}

\begin{abstract}
Renal tissue hypoperfusion and hypoxia are early key elements in the pathophysiology of acute kidney injury of various origins, and may also promote progression from acute injury to chronic kidney disease. Here we describe test interventions that are used to study the control of renal hemodynamics and oxygenation in experimental animals in the context of kidney-specific control of hemodynamics and oxygenation. The rationale behind the use of the individual tests, the physiological responses of renal hemodynamics and oxygenation, the use in preclinical studies, and the possible application in humans are discussed.

This chapter is based upon work from the COST Action PARENCHIMA, a community-driven network funded by the European Cooperation in Science and Technology (COST) program of the European Union, which aims to improve the reproducibility and standardization of renal MRI biomarkers.
\end{abstract}

Key words Renal hemodynamics and oxygenation, In vivo methods, Rats, Test interventions

1 Introduction

Kidney diseases are a global health burden with steadily increasing incidence and prevalence $[1-5]$. Animal studies indicate that acute kidney injuries (AKI) of various origins share one common link in the pathophysiological chain of events, ultimately leading to AKI, as well as to progression from AKI to chronic kidney diseases $(\mathrm{CKD})$ : imbalance between renal oxygen delivery and oxygen demand [6-14]. Renal tissue hypoperfusion and hypoxia have also been suggested to play a pivotal role in the pathophysiology of other kidney diseases including diabetic kidney disease [1519]. These pathophysiological concepts have largely been generated by preclinical studies that used either invasive quantitative probes or noninvasive functional magnetic resonance imaging (MRI) techniques to gain insight into renal hemodynamics and oxygenation. Thus, making ultimate statements on the role of renal hypoperfusion and hypoxia for these renal disorders is elusive 
because in vivo assessment of renal hemodynamics and oxygenation constitutes a challenge.

All modalities available in today's experimental and translational research practice have inherent shortcomings and methodological constraints. Invasiveness is the major disadvantage of the gold standard physiological probes such as perivascular flow probes for measurement of total renal blood flow, laser-Doppler-optodes for assessment of local tissue perfusion, and Clark-type electrodes or fluorescence-quenching optodes for measurements of local tissue partial pressure of oxygen $\left(\mathrm{pO}_{2}\right)$, which precludes their use in humans. While functional MRI including blood oxygenationsensitized $\mathrm{T}_{2}{ }^{*}$ (aka blood oxygenation level-dependent MRI; BOLD-MRI) offers noninvasive techniques to obtain insight into renal perfusion and oxygenation, its major weakness is its qualitative nature. Before it can be used for quantitative characterization of renal tissue perfusion and oxygenation, it needs to be calibrated with the gold standard invasive techniques in various (patho)physiological scenarios [20-24].

The control of renal hemodynamics and oxygenation under physiological as well as under pathophysiological conditions is complex and differs considerably from nonrenal tissue $[8,21,23$, 25-27]. Due to the considerable capacity of the organism's homeostatic control systems to-at least partially-compensate for disturbances of, or injury to, certain control elements, these alterations are often not easily detectable when studied by measuring baseline data only. In order to disentangle these complexities, dedicated reversible test interventions are conceptually appealing. In fact, such interventions can serve three main purposes. First, they are used to gain more insight into the control of renal hemodynamics and oxygenation in healthy animals and in animal models of various kidney diseases $[8,12,25,28-37]$. Second, the tests are used to assess whether a given drug or contrast agent has beneficial or unwarranted effects on the control of renal hemodynamics and oxygenation [38-40]. Finally, dedicated reversible tests are used to achieve calibration of functional MRI data [22, 23].

In this chapter, specifics of the control of renal hemodynamics and oxygenation are outlined first. Then, the individual test procedures are described, and the rationale behind their use, the physiological response of renal hemodynamics and oxygenation, the use in preclinical studies and the possible application in humans are discussed.

This chapter is part of the book Pohlmann A, Niendorf T (eds) (2020) Preclinical MRI of the Kidney-Methods and Protocols. Springer, New York. 


\section{Specifics of Renal Hemodynamics and Oxygenation}

Renal hemodynamics and oxygenation offer a number of striking differences when compared to nonrenal tissue. First, total renal blood flow (RBF) is huge when compared to virtually all other organs on a per gram basis: the kidneys receive about $20 \%$ of the cardiac output under resting conditions. Yet the distribution of blood perfusion differs substantially between the layers: while $100 \%$ of blood flowing into the kidney reaches the cortex, only $15 \%$ of blood that previously passes through the cortex, will reach the medulla. Even intralayer (cortex, outer medulla, and inner medulla) perfusion is quite heterogeneous $[8,41,42]$. In accordance with the high total RBF, the kidneys' oxygen extraction (the difference between the $\mathrm{O}_{2}$ content in the renal arterial and the renal venous blood) is low as compared to the majority of nonrenal tissues. Yet the partial pressure of oxygen $\left(\mathrm{pO}_{2}\right)$ is low in the medulla and also varies considerably within the respective layers, in accordance with the different blood flow distribution [21, 23, $26,43-47]$.

Second, the kidney differs from all other organs with regard to the relationship between metabolism and perfusion. More than 26 thousand millimoles of sodium $\left(\mathrm{Na}^{+}\right)$are filtered in the human glomeruli every day, equivalent to more than $1.5 \mathrm{~kg}$ of table salt. To achieve sodium balance, the amount of salt excreted by the kidneys must exactly match the amount of ingested salt minus the amount of extrarenal loss. Thus, more than $99 \%$ of the filtered sodium must usually be reabsorbed from the tubules. Tubular resorption relies on active transport processes, which account for about $85 \%$ of the kidney's energy expenditure and therefore its $\mathrm{O}_{2}$ consumption. The more sodium is filtered in the glomeruli, the more must be reabsorbed. As glomerular filtration rate (GFR), under the majority of circumstances, increases with increasing $\mathrm{RBF}$, renal $\mathrm{O}_{2}$ consumption also usually increases with increasing renal perfusion. This is in contradistinction to all other organs, where metabolism determines perfusion $[8,48]$.

Third, hormones such as angiotensin II and epinephrine, sympathetic vasomotor nerves, and paracrine mediators such as nitric oxide or adenosine, that control resistance vessels in nonrenal tissues, impinge on intrarenal resistance vessels too, thereby altering renal $\mathrm{O}_{2}$ delivery. However, in the kidney, they additionally affect tubular sodium resorption and thus $\mathrm{O}_{2}$ consumption. Furthermore, their effect on postglomerular vessels can result in divergent responses of RBF and GFR. Finally, adenosine exerts vasodilation in virtually all nonrenal vascular beds, but vasoconstriction in the renal cortex $[8,25,48,49]$.

Fourth, the kidney is equipped with efficient mechanisms of autoregulation, that is, the ability to dampen or even to abolish the 
effects that changes in renal arterial pressure would otherwise inevitably have on RBF and GFR. The almost perfect autoregulation of RBF and GFR probably relies on the fact that not just one, but three mechanisms are involved. The first one, the myogenic response (aka Bayliss effect) acts not only on renal resistance vessels but also on brain and gut vessels. The second mechanism, the tubuloglomerular feedback (TGF), and the third one, hitherto just named "third mechanism", are kidney-specific. Renal autoregulatory mechanisms, in particular the TGF and the third mechanism, have been suggested to serve the purpose of balancing $\mathrm{O}_{2}$ delivery, that is, $\mathrm{RBF}$ with metabolic and $\mathrm{O}_{2}$ demands arising from tubular reabsorption. The outer medulla is particularly prone to imbalance between $\mathrm{O}_{2}$ delivery and demand since this layer exhibits a high $\mathrm{O}_{2}$ demand but low $\mathrm{pO}_{2}[21,34,35,50-52]$.

Fifth, intrarenal perfusion is also affected by changes in tubular volume. The tubular volume fraction is quite large and can rapidly change due to alterations in GFR, in tubular outflow toward the pelvis, in tubular fluid resorption, and modulation of the transmural pressure gradient. Since the renal capsule is rather tough, changes in tubular volume will result in circular distension or compression of intrarenal vessels $[23,36]$.

Finally, in addition to the heterogeneous intrarenal blood perfusion, three other factors substantially contribute to the low tissue $\mathrm{pO}_{2}$ and, in particular, to the "physiological hypoxia" in the medulla. First, there is a considerable shunt diffusion of $\mathrm{O}_{2}$ from arteries to veins in the cortex and from descending to ascending vasa recta in the medulla [53-55]. Second, the Fåhræus-Lindqvist effect lowers the hematocrit in the vasa recta supplying the medulla, which lowers the $\mathrm{O}_{2}$ content of blood perfusing parts of the medulla [41, 42]. Third, plasma skimming at intrarenal vessel branches results in different hematocrit and therefore $\mathrm{O}_{2}$ content of blood perfusing the daughter vessels $[41,56]$.

\section{Dedicated Reversible Test Interventions}

\author{
3.1 Short Periods \\ of Occlusion \\ of the Renal Artery or \\ Renal Vein
}

Occlusions of the renal artery (alternatively: the suprarenal aorta) or of the renal vein emulate clinical conditions in which deficient renal perfusion results in deterioration of intrarenal oxygenation. If maintained for longer periods of time these conditions can cause AKI [57-59]. The rationale for performing both of these tests is that renal arterial occlusion and renal venous occlusion have similar effects with regard to renal perfusion and oxygenation, yet opposing effects with regard to intrarenal blood volume. With the onset of aortic occlusion, the inflow of blood into the kidney is abruptly stopped while outflow via the renal vein continues until pressures in intrarenal vessels and in the vena cava are equalized. With the onset of renal venous occlusion, outflow of blood is abruptly stopped 
while inflow via the artery does not cease until the arterial pressureinduced distension of intrarenal vessels is counterbalanced by the resistance of the renal tissue including the rather tough capsule $[22,39,60]$.

In both cases, renal tissue perfusion rapidly decreases and eventually approaches zero flow. As renal $\mathrm{O}_{2}$ consumption remains unaltered at the early stage of occlusions, a rapid and massive decline in renal tissue $\mathrm{pO}_{2}$ results, which, in turn, also reduces blood $\mathrm{pO}_{2}$ and the $\mathrm{O}_{2}$ saturation of hemoglobin $\left(\mathrm{StO}_{2}\right)$ in the intrarenal (micro)vasculature. This intrarenal deoxygenation of hemoglobin $(\mathrm{Hb})$ is aggravated by a progressive rightward shift of the oxyHb dissociation curve during the occlusion due to the intrarenal accumulation of carbon dioxide $\left(\mathrm{CO}_{2}\right)[22,39,60]$.

Yet the opposing changes of renal blood volume have an impact on renal tissue oxygenation. The decrease in tissue $\mathrm{pO}_{2}$ at the onset of the venous occlusion is much slower than at the onset of the arterial occlusion. While renal $\mathrm{O}_{2}$ consumption is similar during both kinds of occlusions, the transiently maintained inflow of oxygenated blood at the onset of venous occlusion increases the intrarenal reservoir of $\mathrm{O}_{2}[22,39,60]$.

The opposing changes in renal blood volume have a massive impact on the changes in blood oxygenation-sensitized $\mathrm{T}_{2}{ }^{*}$ (and its reciprocal value, $\mathrm{R}_{2}{ }^{*}$ ), because $\mathrm{T}_{2}{ }^{*}$ reflects the amount of deoxygenated $\mathrm{Hb}$ (deoxyHb) per tissue volume (voxel) [23]. In case of the venous occlusion with its increase in the vascular volume fraction and thus the increasing amount of deoxyHb per volume, tissue $\mathrm{T}_{2}{ }^{*}$ massively decreases [60]. With the arterial occlusion's decrease of deoxyHb per volume, the decrease in $\mathrm{T}_{2}{ }^{*}$ is small. In fact, it was found significantly smaller than the decrease in $\mathrm{T}_{2}{ }^{*}$ measured during hypoxemia ( $8 \%$ inspiratory oxygen fraction), which is diametrically opposed to the effects of arterial occlusion versus hypoxemia on tissue $\mathrm{pO}_{2}$ (see Fig. 1) $[22,23,36]$.

Short-time (1-3 min) occlusions of the renal artery (or of the suprarenal aorta) have been used in several studies for different scientific purposes. In order to gauge the effects on $\mathrm{T}_{2}{ }^{*}$ and $\mathrm{T}_{2}$ of bolus injections of an X-ray contrast medium into the thoracic aorta of healthy rats, the effect of arterial occlusion (and that of hypoxemia) was quantified in the same rats [36]. En route to calibration of $\mathrm{T}_{2}{ }^{*}$ with quantitative physiological measurements by means of a dedicated hybrid MR-PHYSIOL setup ( see the chapter by Cantow $\mathrm{K}$ et al. "Monitoring Renal Hemodynamics and Oxygenation by Invasive Probes: Experimental Protocol"), suprarenal aortic occlusion was used [22]. In order to ascertain that the superparamagnetic iron oxide nanoparticle (USPIO) preparation, ferumoxytol is suitable as a contrast medium for MR-based assessment of the renal blood volume fraction; its possible unwarranted effects on control of renal hemodynamics and oxygenation were tested by interventions including suprarenal aortic occlusion in rats (see Fig. 2) 

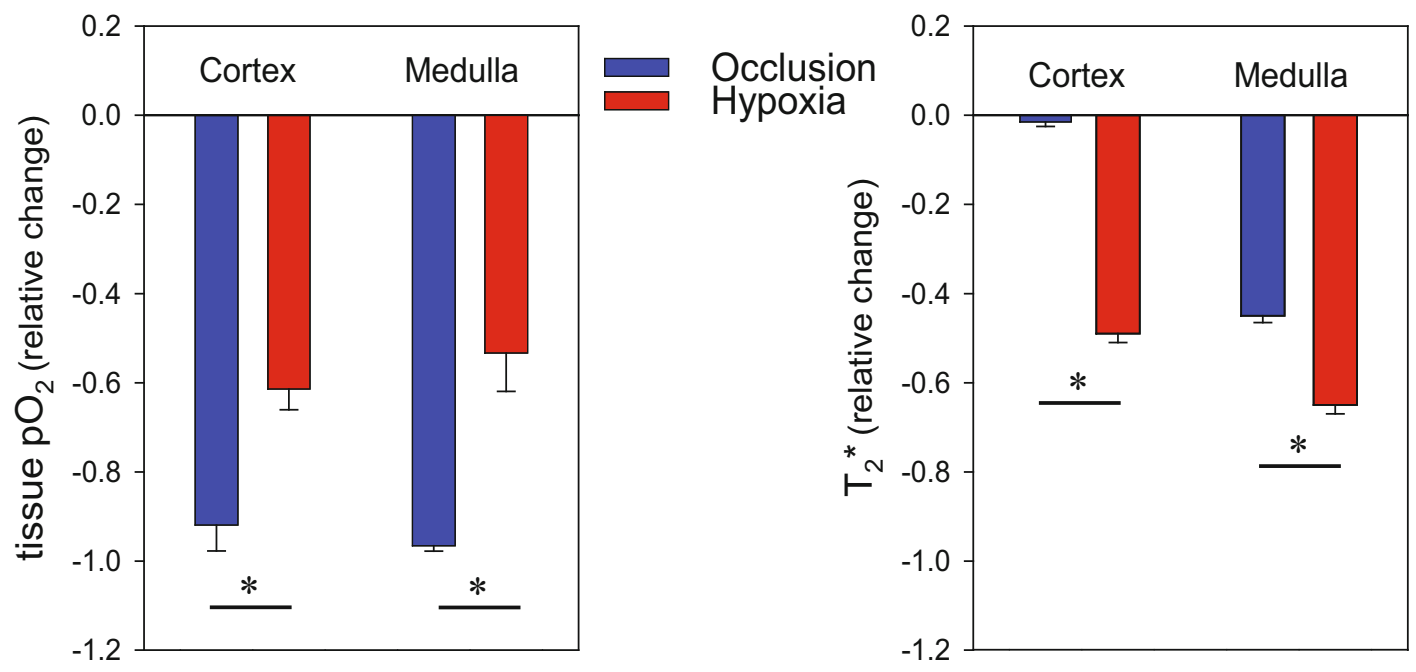

Fig. 1 Comparison of relative changes in renal cortical and medullary tissue $\mathrm{pO}_{2}$ quantified by invasive gold standard fluorescence quenching optodes (left panel) versus relative changes in renal cortical and medullary $\mathrm{T}_{2}{ }^{*}$ (so-called BOLD-MRI, right panel), during short-term occlusion of the suprarenal aorta and short-term hypoxia ( $8 \%$ inspiratory $0_{2}$ fraction), respectively, in anesthetized rats. Data are mean $\pm \mathrm{SEM}$, redrawn from Refs. 22, 36

[38]. Implementing a setup that combines classical invasive probes for $\mathrm{RBF}$, tissue perfusion, and $\mathrm{pO}_{2}$ with newly developed near infrared spectroscopy (NIRS) techniques that enable monitoring of the amount of $\mathrm{Hb}$ per tissue volume and the $\mathrm{O}_{2}$ saturation of $\mathrm{Hb}$ $\left(\mathrm{StO}_{2}\right)$ of intrarenal blood (termed PHYSIOL-NIRS), aortic occlusion was used as one of the test interventions [39]. By means of a dedicated deconvolution procedure developed by our group, the time course of RBF upon the release of the occlusion can be analyzed. This "step-response" analysis allows us to determine the strength of each of the three mechanisms of RBF autoregulation in the whole kidney in vivo, in both healthy rats and rat models of AKI $[30,34,35]$.

Short-time (1-3 min) occlusions of the renal vein were also used for different purposes. In order to establish an optimum dose of the USPIO ferumoxytol in rats for the purpose of $T_{2}{ }^{*}$-based quantification of the renal blood volume fraction in a 9.4T small animal scanner, renal venous occlusion was chosen as the combined effects of the decrease in $\mathrm{O}_{2}$ delivery and the increase in the blood volume fraction; thus, deoxyHb per volume was expected to result in a most prominent decrease in $\mathrm{T}_{2}{ }^{*}$ (see Fig. 3) [60].

Both renal arterial occlusion and renal venous occlusion was performed in the same healthy rats in the PHYSIOL-NIRS setup in order to directly compare their effects [39].

As the implementation of vascular occluders necessitates invasive techniques, these tests can be performed in preclinical studies only. 

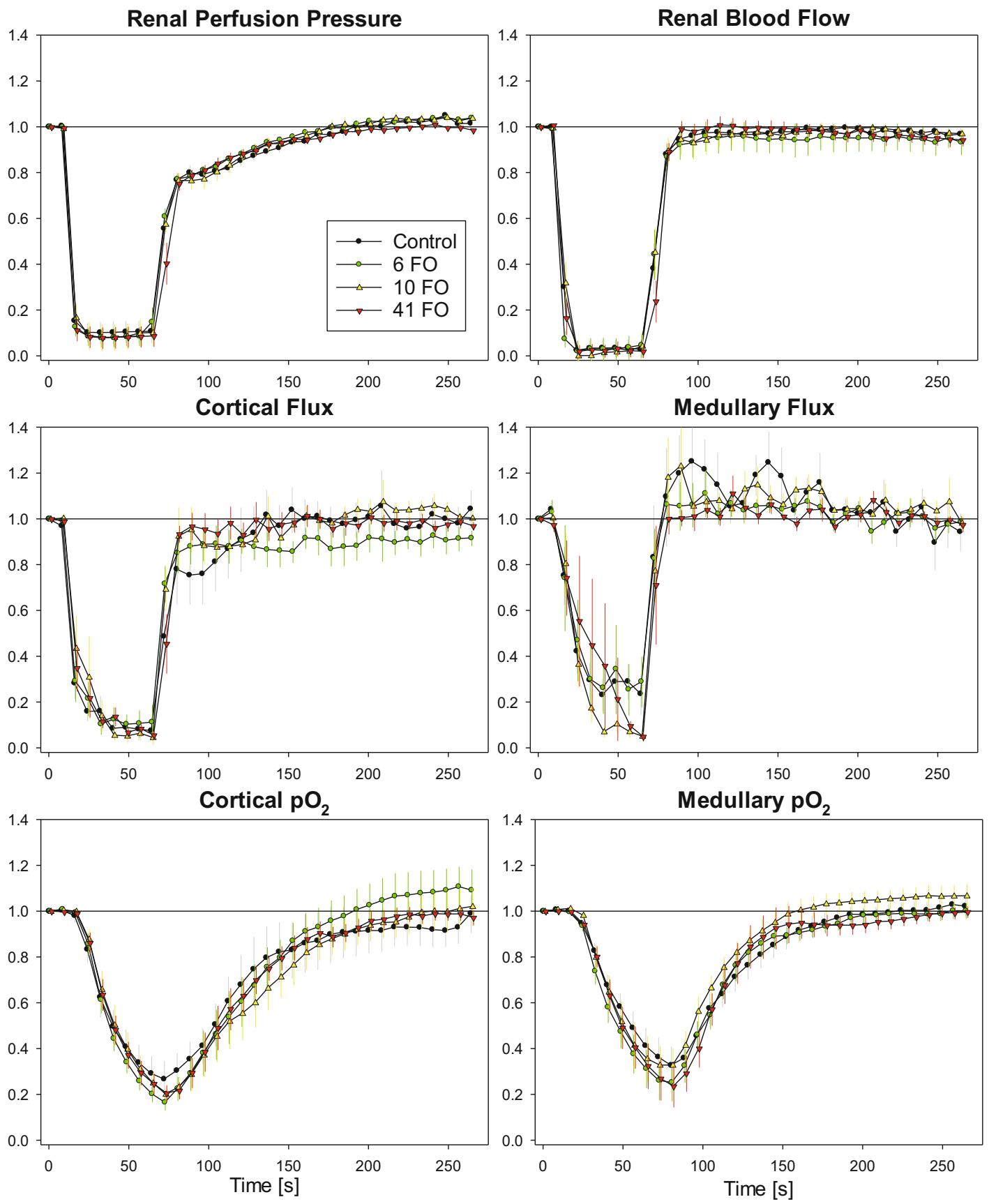

Fig. 2 In order to study whether the USPIO preparation, ferumoxytol (F0), exerts unwarranted effects on regulation of renal hemodynamics and oxygenation, a short-term suprarenal aortic occlusion was employed as test intervention in anesthetized rats [38]. Here, the relative changes (mean $\pm \mathrm{SEM}$ ) in hemodynamics and tissue oxygenation are depicted with F0 dosages of 6,10 , and $41 \mathrm{mg} \mathrm{Fe} / \mathrm{kg}$ body mass, or vehicle (Control) 


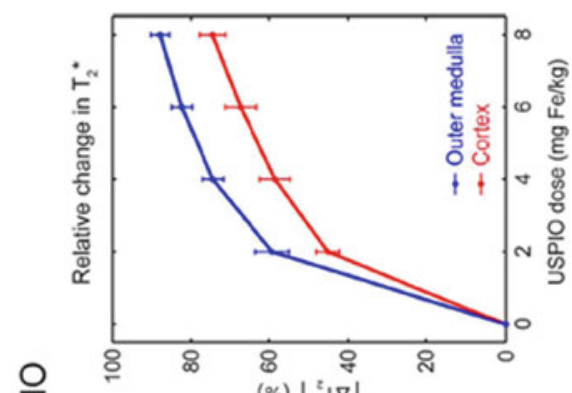

$\frac{0}{\frac{0}{5}}$
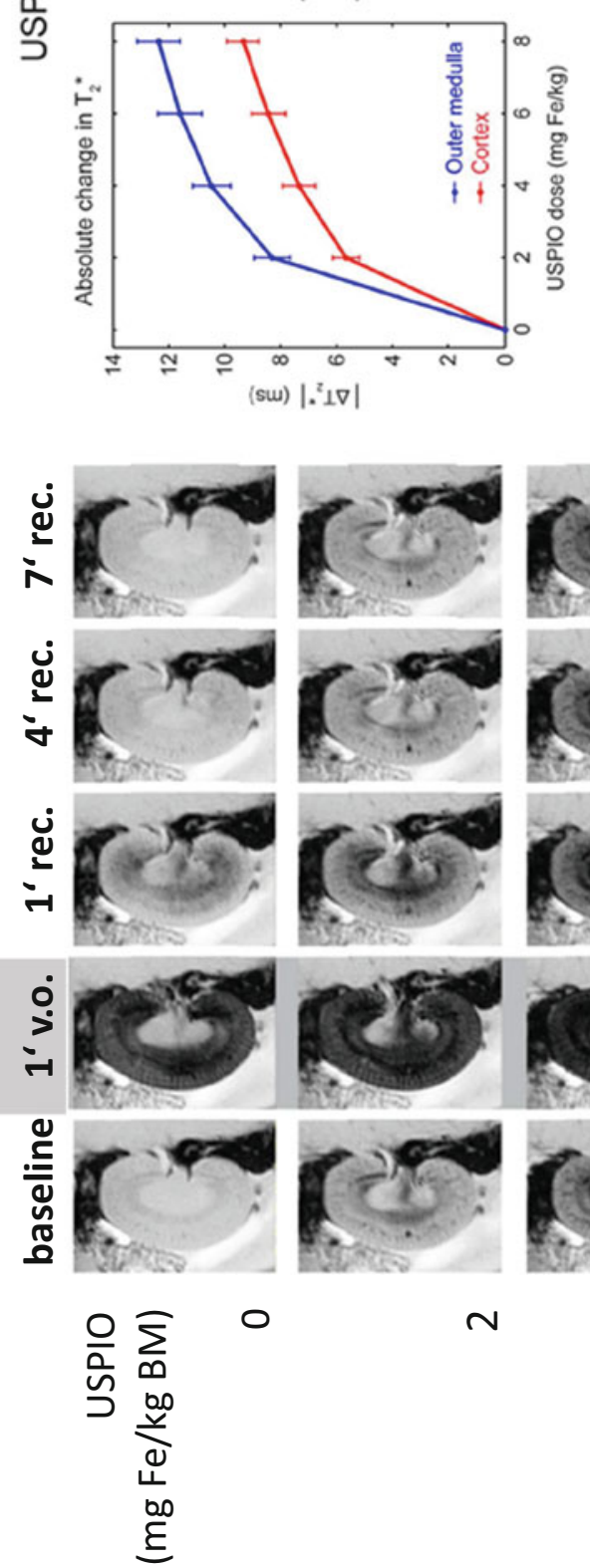
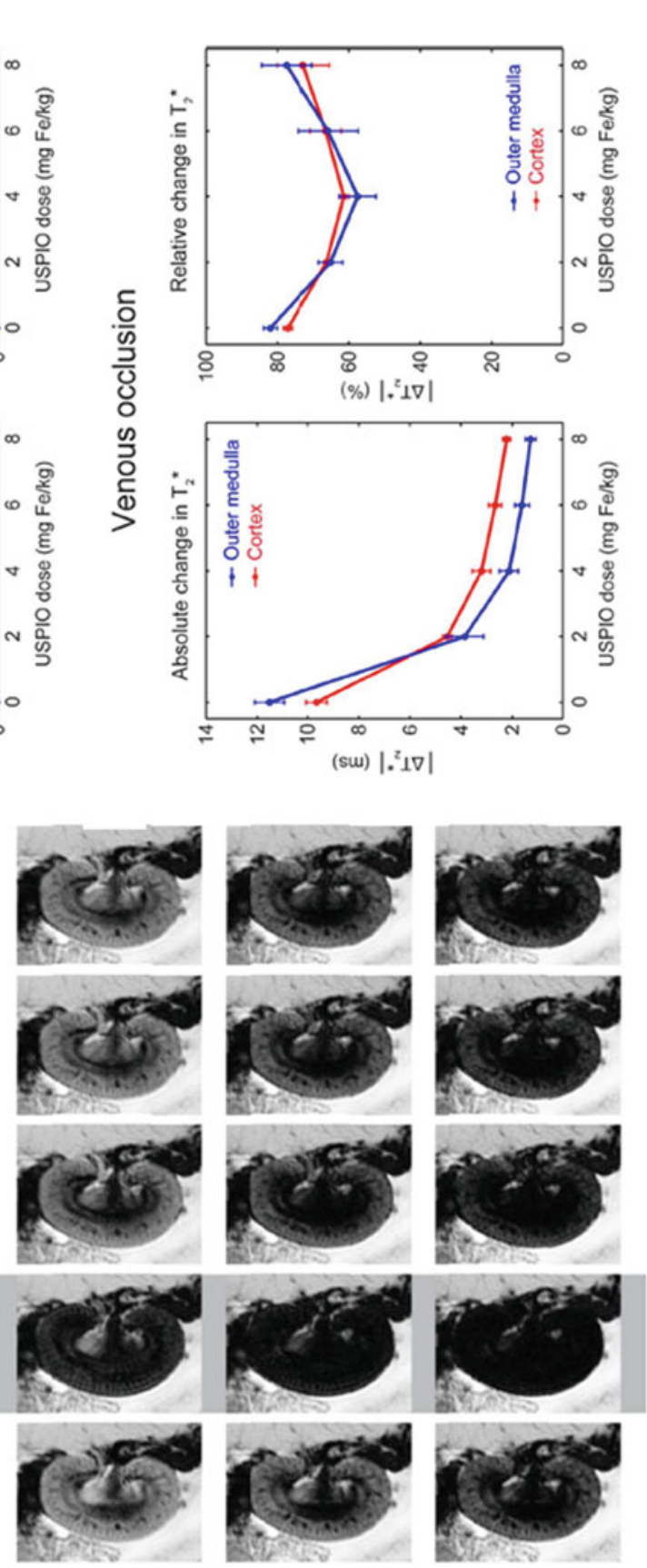

6

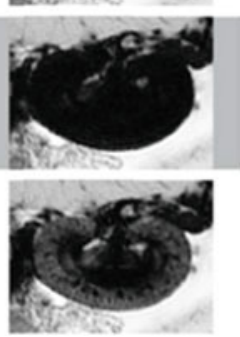

$\infty$
잉 훙우

음 을

등 응

음 중 -

氙㐫

윈은 든

흥 흑

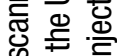

동으음

즐

흥잉

氖

क 등 क्ठ

$\checkmark z^{*} \theta$

๙

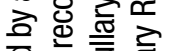

웛 兽

흥 잉등 을

产. 흘 정

ิ⿺ㅇ융 엉

品

유 휴 힌

정 क

|| 돈

등

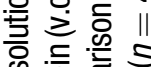

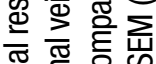

졷 তٓ

के ब

๘

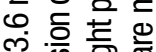

$\|$ 근

它完

을 음

응 흥 훙응

융 을 은

융 엉

힝ㅎㅀ

논

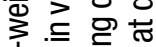

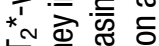

흥ㅎㅁ 인

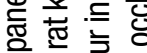

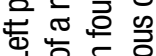

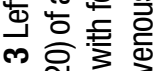

휸 궝 응 
3.2 Servocontrolled Changes in Renal Arterial Pressure

3.3 Short Periods of Changes in the Inspiratory Gas Mixture
Dynamic changes in renal arterial pressure according to different time courses of pressure reduction followed by pressure restoration-be it staircasewise or rampwise changes - enable insights into control of renal hemodynamics and oxygenation including the degree of autoregulation's efficiency and the contributions of the three autoregulatory mechanisms in vivo. This is achieved by a servocontrol system developed by our group, that was utilized to help disentangle the complexities of renal physiology and pathophysiology $[30,31,33,34]$. Moreover, a study that employed such an intervention in a rat model that emulates an early stage of diabetic kidney disease (a type 1 diabetes mellitus-like model induced by administration of streptozotocin 4 weeks before obtaining the data on renal perfusion and oxygenation) unmasked alterations in the control of renal perfusion and oxygenation that would have gone undetected when only baseline data had been obtained [32]. Data on medullary tissue $\mathrm{pO}_{2}$ obtained by invasive probes in this model have been inconsistent, which, among other reasons, may be caused by the spatial heterogeneity of $\mathrm{pO}_{2}$ within the renal medulla [15-17]. A recent study did not find any significant differences in baseline data on $\mathrm{RBF}$ and cortical and medullary tissue $\mathrm{pO}_{2}$ among healthy control rats, diabetic rats, and diabetic rats treated with the antidiabetic liraglutide (a glucagon-like peptide 1 agonist approved for patients suffering from type 2 diabetes). However, as depicted by Fig. 4, the response to ramp-wise reduction and restoration of renal arterial pressure differed considerably among these groups [32].

Again, as the implementation of a vascular occluder necessitates invasive techniques, such studies can be performed in preclinical studies only.

Hyperoxia, hypoxia, and hypercapnia primarily alter blood oxygenation. Renal $\mathrm{O}_{2}$ delivery is determined by renal perfusion and by the arterial $\mathrm{O}_{2}$ content. The latter is determined, among other factors, by the inspiratory fraction of oxygen $\left(\mathrm{FiO}_{2}\right)$, and, due to the effect of $\mathrm{CO}_{2}$ on the oxyHb dissociation curve, also by the inspiratory fraction of $\mathrm{CO}_{2}\left(\mathrm{FiCO}_{2}\right)$.

Increasing the $\mathrm{FiO}_{2}$ from $21 \%$ (normoxia) to $100 \%$ (hyperoxia) results in a substantial increase in arterial $\mathrm{pO}_{2}$ (usually four- to fivefold), whereas the increase in arterial $\mathrm{O}_{2}$ content is very small, because most of the $\mathrm{Hb}$ in arterial blood is already $\mathrm{O}_{2}$ saturated under normoxic conditions. Yet the increase in arterial $\mathrm{pO}_{2}$ enhances the driving force for diffusion of $\mathrm{O}_{2}$ from intrarenal vessels to tissue as well as from intrarenal arteries to veins. As a consequence, the increase in renal tissue $\mathrm{pO}_{2}$ is substantial, whereby medullary $\mathrm{pO}_{2}$ increases less than cortical $\mathrm{pO}_{2}$, due to arteriovenous diffusive $\mathrm{O}_{2}$ shunting, which reduces the $\mathrm{O}_{2}$ content of arterial blood that perfuses the medulla $[22,26,39,53-$ 55]. Renal $\mathrm{T}_{2}{ }^{*}$ changes exerted by hyperoxia are small 

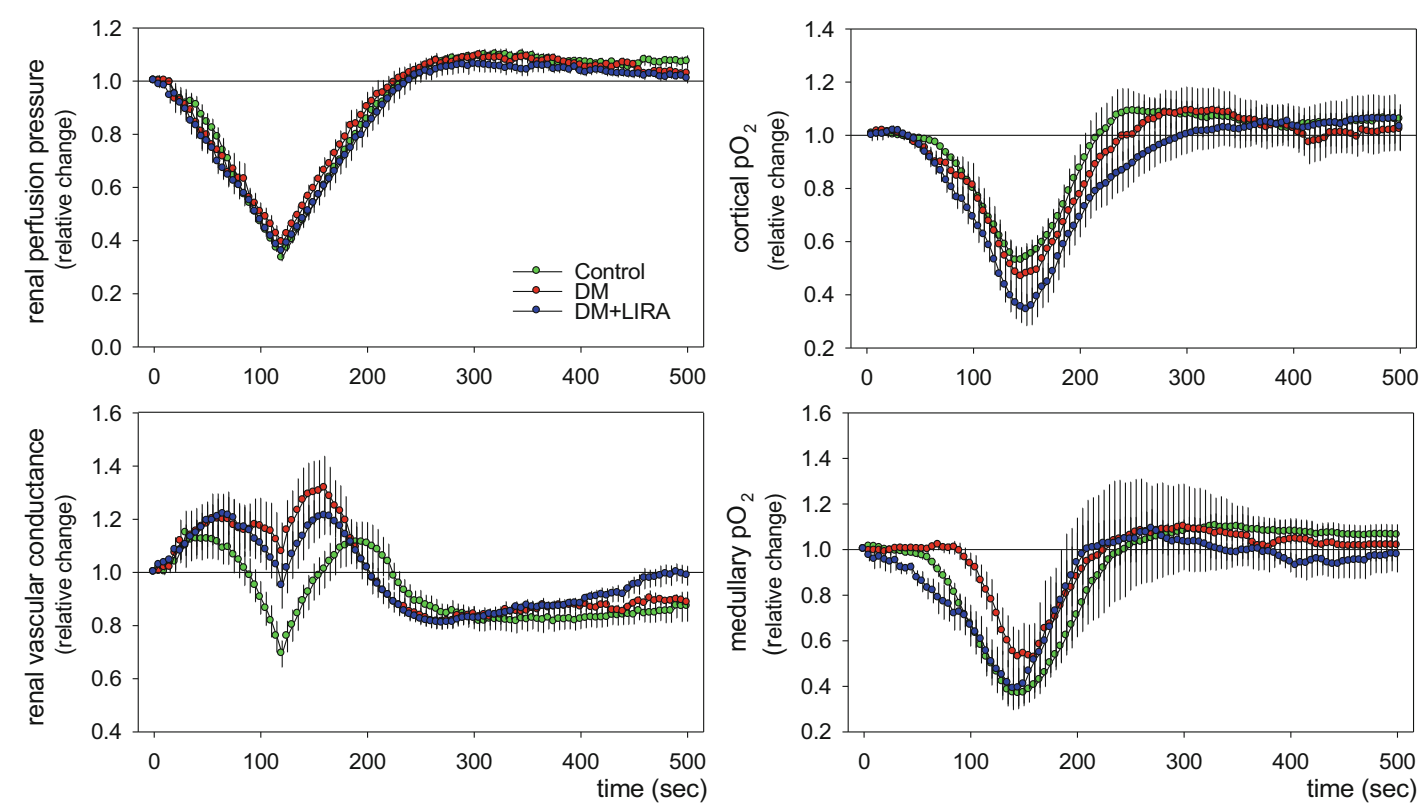

Fig. 4 Changes of invasively measured parameters of renal hemodynamics and oxygenation during ramp-wise reduction in renal perfusion pressure followed by ramp-wise pressure restoration in anesthetized rats. Conductance values (the reciprocal of vascular resistance) were calculated by dividing the respective perfusion values by renal perfusion pressure, in order to distinguish flow changes that result from passive circular distension/compression of vessels from those actively exerted by vascular smooth muscles. Three groups were studied: a healthy control group, a group in which a diabetes mellitus type 1-like disorder (DM) was induced by streptozotocin 4 weeks before obtaining the data, and a third group in which DM was induced and the antidiabetic liraglutide administered for 3 weeks (DM + LIRA). Values (mean \pm SEM) are given as relative changes from baseline [32]

[22]. While the amount of deoxyHb in arterial blood is barely changed, the increase in blood $\mathrm{pO}_{2}$ in intrarenal veins that results from the higher arteriovenous $\mathrm{pO}_{2}$ difference decreases venous deoxyHb. While primarily altering blood oxygenation, the hyperoxic stimulus has also secondary effects: it results in vasoconstriction, preferentially in nonrenal vascular beds, which leads to an increase in arterial pressure [22, 31, 39].

The primary effect of reducing the $\mathrm{FiO}_{2}$ (typically to either $8 \%$ or $10 \%$, with durations of 3-12 min, in rat studies) is a decrease in oxygenation of arterial blood (hypoxemia) with the consequent reduction in renal $\mathrm{O}_{2}$ supply. With ongoing $\mathrm{O}_{2}$ consumption, this does per se result in a decrease in renal tissue $\mathrm{pO}_{2}$. Yet renal $\mathrm{O}_{2}$ supply is further diminished by hypoxia-induced extrarenal vasodilation that results in a drop in arterial pressure with ensuing decrease in $\operatorname{RBF}[22,31,39,59]$. Whether this is aggravated of alleviated by constriction or dilation, respectively, of the renal vasculature depends on the degree of hypoxia: in anesthetized rats, $\mathrm{FiO}_{2}$ of $8 \%$ results in renal vasoconstriction while $10 \%$ results in vasodilation $[22,31,39]$. The combined effect of hypoxemia and 
reduced $\mathrm{RBF}$ on renal $\mathrm{O}_{2}$ supply leads to a major mismatch with $\mathrm{O}_{2}$ consumption, that massively reduces tissue $\mathrm{pO}_{2}$ as well as $\mathrm{T}_{2}{ }^{*}$ (see Fig. 1) $[22,39]$. A further secondary effect of arterial hypoxemia is increased ventilation triggered by arterial chemoreceptors. The ensuing decrease in arterial $\mathrm{pCO}_{2}$ shifts the oxyHb dissociation curve to the left, that is, $\mathrm{O}_{2}$ is hindered from being released by $\mathrm{Hb}$, which further aggravates the tissue hypoxia [61, 62].

With the hypercapnic stimulus (increasing $\mathrm{FiCO}_{2}$ to $5 \%$ ) the opposite effect is achieved, namely a rightward shift of the oxyHb dissociation curve. This would per se result in a decrease in $\mathrm{StO}_{2}$ and an increase in blood and tissue $\mathrm{pO}_{2}$. However, while the increase in tissue $\mathrm{pO}_{2}$ is substantial, the $\mathrm{StO}_{2}$ decrease is meagre [39]. The major reason that $\mathrm{StO}_{2}$ does not decrease much is that increased $\mathrm{pCO}_{2}$ of arterial blood is a very strong stimulus for ventilation, again mediated by arterial chemoreceptors [61, 62].

Hyperoxic, hypoxic, and hypercapnic tests have been used in a multitude of preclinical in vivo studies. With regard to the kidney this includes but is not limited to studies on the control of renal hemodynamics and oxygenation in healthy animals and models of kidney diseases $[26,27,31,53-55,59]$, experiments that aimed at calibration of $\mathrm{T}_{2}{ }^{*}$ by means of the MR-PHYSIOL setup (see Fig. 5), [22] studies on the $\mathrm{T}_{2}{ }^{*}$ effect of an X-ray contrast medium, [36] assessment of possible unwarranted effects of the USPIO ferumoxytol, [38] and experiments en route to the PHYSIOL-NIRS setup [39].
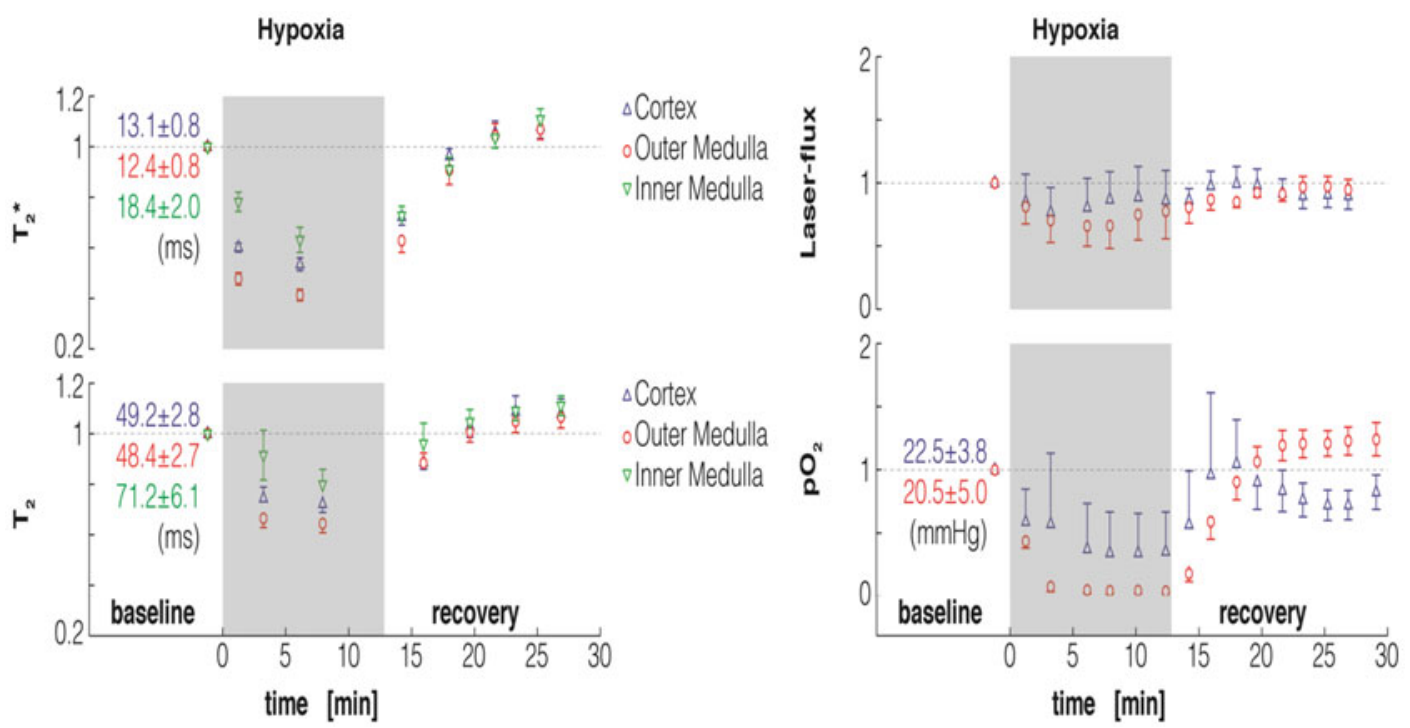

Fig. 5 Time courses of selected invasively measured data and MR parameters acquired simultaneously throughout baseline, a period of hypoxia $\left(\mathrm{FiO}_{2}=8 \%\right)$, and recovery in anesthetized rats by means of a dedicated MR-PHYSIOL hybrid setup (for details see text). Data (mean \pm SEM) are relative changes from baseline, redrawn from Ref. 22 


\subsection{Administration of Drugs and Endogenous Vasoactive Substances}

Given the broad therapeutic use of pure oxygen, short-term tests with $100 \% \mathrm{FiO}_{2}$ should pose no problem for studies in humans, whereas hypoxic challenges are precluded in humans, for obvious ethical reasons. Hypercapnia has been used for decades in humans, in particular, for the study of cerebrovascular reactivity, and should thus be employed in preclinical and clinical studies on renal hemodynamics and oxygenation as well $[63,64]$.

Furosemide is the "classic" loop diuretic: its major action is the inhibition of the sodium-potassium-two-chloride cotransporter in the apical membrane of tubular epithelial cells of the thick ascending limb of Henle's loop. The primary effect is an increase in urine flow rate and in urinary sodium and potassium excretion. As less tubular resorption necessitates less renal $\mathrm{O}_{2}$ consumption, administration of furosemide leads to an increase in renal tissue $\mathrm{pO}_{2}$ $[65,66]$. In accordance, increases in renal $\mathrm{T}_{2}{ }^{*}$ (or decreases in its reciprocal value $\mathrm{R}_{2}{ }^{*}$ ) have been observed in a multitude of preclinical as well as clinical studies (see Fig. 6) [37, 66-69]. It must be noted, however, that the increase in $\mathrm{T}_{2}{ }^{*}$ upon furosemide does not solely rely on improved oxygenation. First, the increase in tubular fluid downstream of the thick ascending limb will increase the transmural pressure gradient, thereby compressing intrarenal

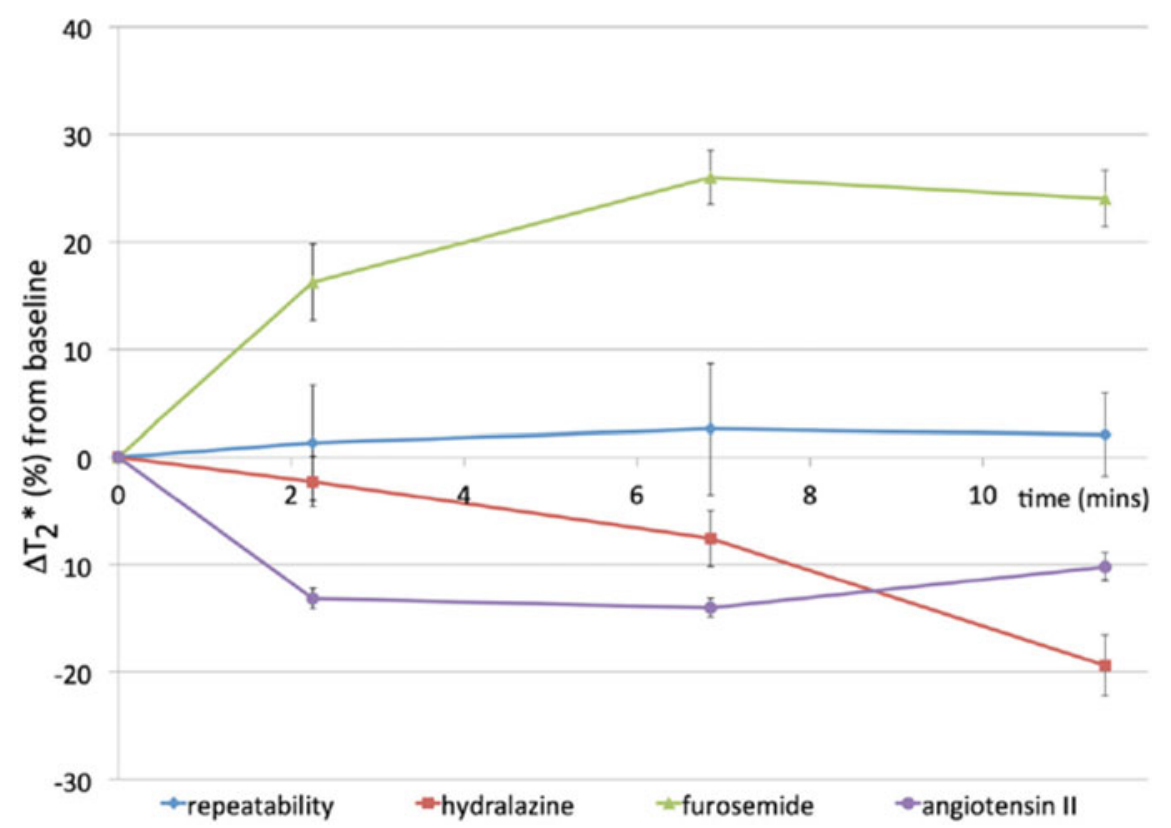

Fig. 6 Effect of injections of furosemide ( $5 \mathrm{mg} / \mathrm{kg}$ body mass), hydralazine $(5 \mathrm{mg} / \mathrm{kg})$, angiotensin II $(0.5 \mu \mathrm{g} /$ $\min / \mathrm{kg}$ ), and saline (repeatability) on renal BOLD as recorded by means of a $1.5 \mathrm{~T}$ clinical MR scanner (Magnetom Avanto, Siemens Healthcare), using a multiple gradient echo sequence (TR $=300 \mathrm{~ms}, \mathrm{TE}=5$, $10,20,30$, and $40 \mathrm{~ms}$, voxel size $0.6 \times 0.6 \mathrm{~mm}$ in-plane and $5 \mathrm{~mm}$ slice thickness) in rats in vivo. Data are mean \pm SEM of median $\mathrm{ROI}$ values [37] 
vessels with the ensuing decrease in the amount of deoxyHb per tissue volume. Second, furosemide inhibits the TGF, thereby compromising renal autoregulation with the possible consequence of an increase in $\operatorname{RBF}[34,35,50]$.

The use of the furosemide test in both preclinical and clinical MR studies is nowadays as widespread that it is almost regarded as a gold standard. However, whether it fulfils all expectations regarding its use as a diagnostic tool in patients suffering from various kidney diseases, remains to be seen [68].

Administration of furosemide is a reversible intervention insofar as its direct effects vanish with the excretion of the drug. However, it leaves the organism with deficits in water, sodium, and potassium. These should ideally be replenished-be it per os or by means of infusions of a balanced electrolyte solution.

Bolus injections of adenosine cause a rapid drop in arterial pressure due to its vasodilatory effect on nonrenal resistance vessels. In the renal cortical vascular bed, it exerts vasoconstriction $[39,49]$. The consequence of these two effects is a substantial decrease in RBF followed by a smaller decrease in cortical tissue $\mathrm{pO}_{2}$. All these effects vanish rapidly, lasting less than a minute for the hemodynamics and less than $2 \mathrm{~min}$ for the cortical $\mathrm{pO}_{2}$ in rats [39].

Whereas the role of adenosine in various renal control mechanisms including the TGF as well as the potentially beneficial effect of adenosine receptor antagonists for prevention of $\mathrm{X}$-ray contrast media-induced AKI have been intensively studied, $[49,70]$ the adenosine test has seldom been used to study renal hemodynamics and oxygenation. This may appear surprising, as injections of adenosine-be it intravenously or into coronary arteries-in patients suffering from coronary disease is quite established $[71,72]$. While the risk for a decrease in renal cortical $\mathrm{pO}_{2}$ in patients must not be ignored-even if it is lasting less than $2 \mathrm{~min}$, the test should at least find wider use in preclinical studies.

This work was funded, in part (Kathleen Cantow and Erdmann Seeliger) by the German Research Foundation (Gefoerdert durch die Deutsche Forschungsgemeinschaft (DFG), Project number/ Projektnummer 394046635, SFB 1365, RENOPROTECTION). The authors wish to thank Ariane Anger and Andrea Gerhardt for expert technical assistance.

This chapter is based upon work from COST Action PAR ENCHIMA, supported by European Cooperation in Science and Technology (COST). COST (www.cost.eu) is a funding agency for research and innovation networks. COST Actions help connect research initiatives across Europe and enable scientists to enrich 
their ideas by sharing them with their peers. This boosts their research, career, and innovation.

PARENCHIMA (renalmri.org) is a community-driven Action in the COST program of the European Union, which unites more than 200 experts in renal MRI from 30 countries with the aim to improve the reproducibility and standardization of renal MRI biomarkers.

\section{References}

1. Fortrie G, de Geus HRH, Betjes MGH (2019) The aftermath of acute kidney injury: a narrative review of long-term mortality and renal function. Crit Care 23(1):24. https://doi. org/10.1186/s13054-019-2314-z

2. Selby NM, Taal MW (2019) Long-term outcomes after AKI-a major unmet clinical need. Kidney Int 95(1):21-23. https://doi.org/10. $1016 /$ j.kint.2018.09.005

3. Zuk A, Bonventre JV (2019) Recent advances in acute kidney injury and its consequences and impact on chronic kidney disease. Curr Opin Nephrol Hypertens 28(4):397-405. https:// doi.org/10.1097/mnh.0000000000000504

4. Levin A, Tonelli M, Bonventre J, Coresh J, Donner JA, Fogo AB, Fox CS, Gansevoort RT, Heerspink HJL, Jardine M, Kasiske B, Kottgen A, Kretzler M, Levey AS, Luyckx VA, Mehta R, Moe O, Obrador G, Pannu N, Parikh CR, Perkovic V, Pollock C, Stenvinkel P, Tuttle KR, Wheeler DC, Eckardt KU (2017) Global kidney health 2017 and beyond: a roadmap for closing gaps in care, research, and policy. Lancet 390(10105):1888-1917. https://doi.org/ 10.1016/s0140-6736(17)30788-2

5. Bello AK, Levin A, Tonelli M, Okpechi IG, Feehally J, Harris D, Jindal K, Salako BL, Rateb A, Osman MA, Qarni B, Saad S, Lunney $\mathrm{M}$, Wiebe $\mathrm{N}$, Ye F, Johnson DW (2017) Assessment of global kidney health care status. JAMA 317(18):1864-1881. https://doi.org/10.1001/jama.2017.4046

6. Brezis M, Rosen S (1995) Hypoxia of the renal medulla--its implications for disease. N Engl J Med 332:647-655

7. Seeliger E, Sendeski M, Rihal CS, Persson PB (2012) Contrast-induced kidney injury: mechanisms, risk factors, and prevention. Eur Heart J 33(16):2007-2015

8. Evans RG, Ince C, Joles JA, Smith DW, May CN, O'Connor PM, Gardiner BS (2013) Haemodynamic influences on kidney oxygenation: the clinical implications of integrative physiology. Clin Exp Pharmacol Physiol 40:106-122
9. Evans RG, Ow CP, Bie P (2015) The chronic hypoxia hypothesis: the search for the smoking gun goes on. Am J Physiol Renal Physiol 308 (2):F101-F102

10. Shu S, Wang Y, Zheng M, Liu Z, Cai J, Tang C, Dong Z (2019) Hypoxia and hypoxiainducible factors in kidney injury and repair. Cell 8(3):207. https://doi.org/10.3390/ cells 8030207

11. Hultstrom M, Becirovic-Agic M, Jonsson S (2018) Comparison of acute kidney injury of different etiology reveals in-common mechanisms of tissue damage. Physiol Genomics 50 (3):127-141. https://doi.org/10.1152/ physiolgenomics.00037.2017

12. Calzavacca P, Evans RG, Bailey M, Bellomo R, May CN (2015) Cortical and medullary tissue perfusion and oxygenation in experimental septic acute kidney injury. Crit Care Med 43 (10):e431-e439

13. Fähling M, Seeliger E, Patzak A, Persson PB (2017) Understanding and preventing contrast-induced acute kidney injury. Nat Rev Nephrol 13(3):169-180

14. Ma S, Evans RG, Iguchi N, Tare M, Parkington HC, Bellomo R, May CN, Lankadeva YR (2019) Sepsis-induced acute kidney injury: a disease of the microcirculation. Microcirculation 26(2):e12483. https://doi.org/10. $1111 /$ micc. 12483

15. Palm F, Carlsson PO, Hansell P, Hellberg O, Nygren A, Liss P (2003) Altered response in renal blood flow and oxygen tension to contrast media in diabetic rats. Acta Radiol 44 (3):347-353

16. Palm F, Cederberg J, Hansell P, Liss P, Carlsson PO (2003) Reactive oxygen species cause diabetes-induced decrease in renal oxygen tension. Diabetologia 46(8):1153-1160

17. dos Santos EA, Li LP, Ji L, Prasad PV (2007) Early changes with diabetes in renal medullary hemodynamics as evaluated by fiberoptic probes and BOLD magnetic resonance imaging. Investig Radiol 42(3):157-162. https:// 
doi.org/10.1097/01.rli.0000252492. 96709.36

18. Calvin AD, Misra S, Pflueger A (2010) Contrast-induced acute kidney injury and diabetic nephropathy. Nat Rev Nephrol 6 (11):679-688

19. Hansell P, Welch WJ, Blantz RC, Palm F (2013) Determinants of kidney oxygen consumption and their relationship to tissue oxygen tension in diabetes and hypertension. Clin Exp Pharmacol Physiol 40(2):123-137

20. Evans RG, Gardiner BS, Smith DW, O'Connor PM (2008) Methods for studying the physiology of kidney oxygenation. Clin Exp Pharmacol Physiol 35(12):1405-1412

21. Pohlmann A, Cantow K, Hentschel J, Arakelyan K, Ladwig $M$, Flemming $B$, Hoff U, Persson PB, Seeliger E, Niendorf T (2013) Linking non-invasive parametric MRI with invasive physiological measurements (MR-PHYSIOL): towards a hybrid and integrated approach for investigation of acute kidney injury in rats. Acta Physiol (Oxf) 207 (4):673-689

22. Pohlmann A, Arakelyan K, Hentschel J, Cantow K, Flemming B, Ladwig $M$, Waiczies S, Seeliger E, Niendorf T (2014) Detailing the relation between renal $\mathrm{T} 2 *$ and renal tissue pO2 using an integrated approach of parametric magnetic resonance imaging and invasive physiological measurements. Investig Radiol 49(8):547-560

23. Niendorf T, Pohlmann A, Arakelyan K, Flemming B, Cantow K, Hentschel J, Grosenick D, Ladwig M, Reimann H, Klix S, Waiczies S, Seeliger E (2015) How BOLD is blood oxygenation-dependent (BOLD) magnetic resonance imaging of the kidney? Opportunities, challenges and future directions. Acta Physiol (Oxf) 213(1):19-38

24. Hirakawa Y, Tanaka T, Nangaku M (2017) Renal hypoxia in CKD; pathophysiology and detecting methods. Front Physiol 8:99. https://doi.org/10.3389/fphys.2017.00099

25. Calzavacca P, Evans RG, Bailey M, Bellomo R, May CN (2015) Variable responses of regional renal oxygenation and perfusion to vasoactive agents in awake sheep. Am J Physiol Regul Integr Comp Physiol 309(10):R1226-R1233

26. Evans RG, Gardiner BS, Smith DW, O'Connor PM (2008) Intrarenal oxygenation: unique challenges and the biophysical basis of homeostasis. Am J Physiol Renal Physiol 295 (5):1259-1270

27. Evans RG, Goddard D, Eppel GA, O'Connor PM (2011) Factors that render the kidney susceptible to tissue hypoxia in hypoxemia. Am J
Physiol Regul Integr Comp Physiol 300(4): R931-R940

28. Emans TW, Janssen BJ, Pinkham MI, Ow CP, Evans RG, Joles JA, Malpas SC, Krediet CT, Koeners MP (2016) Exogenous and endogenous angiotensin-II decrease renal cortical oxygen tension in conscious rats by limiting renal blood flow. J Physiol 594(21):6287-6300. https://doi.org/10.1113/jp270731

29. Evans RG, Madden AC, Denton KM (2000) Diversity of responses of renal cortical and medullary blood flow to vasoconstrictors in conscious rabbits. Acta Physiol Scand 169 (4):297-308

30. Seeliger E, Flemming B, Wronski T, Ladwig M, Arakelyan K, Godes M, Mockel M, Persson PB (2007) Viscosity of contrast media perturbs renal hemodynamics. J Am Soc Nephrol 18 (11):2912-2920

31. Flemming B, Seeliger E, Wronski T, Steer K, Arenz N, Persson PB (2000) Oxygen and renal hemodynamics in the conscious rat. J Am Soc Nephrol 11(1):18-24

32. Ferrara F, Cantow K, Flemming B, Skalweit A, Ladwig M, Fähling M, Seeliger E (2017) Effects of liraglutide on control of renal hemodynamics and oxygenation in diabetic rats. Acta Physiol (Oxf) 219(Suppl. 711):38

33. Flemming B, Arenz N, Seeliger E, Wronski T, Steer K, Persson PB (2001) Time-dependent autoregulation of renal blood flow in conscious rats. J Am Soc Nephrol 12(11):2253-2262

34. Seeliger E, Wronski T, Ladwig M, Dobrowolski L, Vogel T, Godes M, Persson PB, Flemming B (2009) The renin-angiotensin system and the third mechanism of renal blood flow autoregulation. Am J Physiol Renal Physiol 296(6):Fl334-F1345

35. Wronski T, Seeliger E, Persson PB, Forner C, Fichtner C, Scheller J, Flemming B (2003) The step response: a method to characterize mechanisms of renal blood flow autoregulation. Am J Physiol Renal Physiol 285(4): F758-F764

36. Arakelyan K, Cantow K, Hentschel J, Flemming B, Pohlmann A, Ladwig M, Niendorf T, Seeliger E (2013) Early effects of an $\mathrm{x}$-ray contrast medium on renal $\mathrm{T}_{2}{ }^{*} / \mathrm{T}_{2}$ MRI as compared to short-term hyperoxia, hypoxia and aortic occlusion in rats. Acta Physiol 208(2):202-213

37. Jerome NP, Boult JK, Orton MR, d'Arcy J, Collins DJ, Leach MO, Koh DM, Robinson SP (2016) Modulation of renal oxygenation and perfusion in rat kidney monitored by quantitative diffusion and blood oxygen level dependent magnetic resonance imaging on a 
clinical 1.5T platform. BMC Nephrol 17 (1):142. https://doi.org/10.1186/s12882016-0356-x

38. Cantow K, Pohlmann A, Flemming B, Ferrara F, Waiczies S, Grosenick D, Niendorf T, Seeliger E (2016) Acute effects of ferumoxytol on regulation of renal hemodynamics and oxygenation. Sci Rep 6:29965. https://doi.org/10.1038/srep29965

39. Grosenick D, Cantow K, Arakelyan K, Wabnitz H, Flemming B, Skalweit A, Ladwig M, Macdonald R, Niendorf T, Seeliger E (2015) Detailing renal hemodynamics and oxygenation in rats by a combined nearinfrared spectroscopy and invasive probe approach. Biomed Opt Express 6(2):309-323

40. Seeliger E, Cantow K, Arakelyan K, Ladwig M, Persson PB, Flemming B (2014) Low-dose nitrite alleviates early effects of an X-ray contrast medium on renal hemodynamics and oxygenation in rats. Investig Radiol 49(2):70-77

41. Edwards A, Silldforff EP, Pallone TL (2000) The renal medullary microcirculation. Front Biosci 5:E36-E52

42. Zimmerhackl BL, Robertson CR, Jamison RL (1987) The medullary microcirculation. Kidney Int 31(2):641-647

43. Schurek HJ (1988) Kidney medullary hypoxia: a key to understanding acute renal failure? die Nierenmarkhypoxie: ein Schlussel zum Verstandnis des akuten Nierenversagens? Klin Wochenschr 66(18):828-835

44. Baumgartl H, Leichtweiss HP, Lubbers DW, Weiss C, Huland H (1972) The oxygen supply of the dog kidney: measurements of intrarenal $\mathrm{pO}_{2}$. Microvasc Res 4(3):247-257

45. Lubbers DW, Baumgartl H (1997) Heterogeneities and profiles of oxygen pressure in brain and kidney as examples of the $\mathrm{pO}_{2}$ distribution in the living tissue. Kidney Int 51(2):372-380

46. Evans RG, Ow CPC (2018) Heterogeneity of renal cortical oxygenation: seeing is believing. Kidney Int 93(6):1278-1280. https://doi. org/10.1016/j.kint.2018.01.039

47. Hirakawa Y, Mizukami K, Yoshihara T, Takahashi I, Khulan P, Honda T, Mimura I, Tanaka T, Tobita S, Nangaku M (2018) Intravital phosphorescence lifetime imaging of the renal cortex accurately measures renal hypoxia. Kidney Int 93(6):1483-1489. https://doi. org/10.1016/j.kint.2018.01.015

48. Evans RG, Harrop GK, Ngo JP, Ow CP, O'Connor PM (2014) Basal renal $\mathrm{O}_{2}$ consumption and the efficiency of $\mathrm{O}_{2}$ utilization for $\mathrm{Na}^{+}$reabsorption. Am J Physiol Renal Physiol 306(5):F551-F560
49. Vallon V, Muhlbauer B, Osswald H (2006) Adenosine and kidney function. Physiol Rev 86(3):901-940

50. Just A (2007) Mechanisms of renal blood flow autoregulation: dynamics and contributions. Am J Physiol Regul Integr Comp Physiol 292 (1):Rl-R17

51. O'Connor PM (2006) Renal oxygen delivery: matching delivery to metabolic demand. Clin Exp Pharmacol Physiol 33(10):961-967

52. Blantz RC, Weir MR (2004) Are the oxygen costs of kidney function highly regulated? Curr Opin Nephrol Hypertens 13(1):67-71

53. Schurek HJ, Jost U, Baumgartl H, Bertram H, Heckmann U (1990) Evidence for a preglomerular oxygen diffusion shunt in rat renal cortex. Am J Physiol 259(6 Pt 2):F910-F915

54. Ngo JP, Ow CP, Gardiner BS, Kar S, Pearson JT, Smith DW, Evans RG (2016) Diffusive shunting of gases and other molecules in the renal vasculature: physiological and evolutionary significance. Am J Physiol Regul Integr Comp Physiol 311(5):R797-r810. https:// doi.org/10.1152/ajpregu.00246.2016

55. Leong CL, Anderson WP, O'Connor PM, Evans RG (2007) Evidence that renal arterialvenous oxygen shunting contributes to dynamic regulation of renal oxygenation. Am J Physiol Renal Physiol 292:F1726-F1733

56. Pappenheimer JR, Kinter WB (1956) Hematocrit ratio of blood within mammalian kidney and its significance for renal hemodynamics. Am J Physiol 185:377

57. Hoff U, Lukitsch I, Chaykovska L, Ladwig M, Arnold C, Manthati VL, Fuller TF, Schneider W, Gollasch $M$, Muller DN, Flemming B, Seeliger E, Luft FC, Falck JR, Dragun D, Schunck WH (2011) Inhibition of 20-HETE synthesis and action protects the kidney from ischemia/reperfusion injury. Kidney Int 79(1):57-65

58. Hosszu A, Antal Z, Lenart L, Hodrea J, Koszegi S, Balogh DB, Banki NF, Wagner L, Denes A, Hamar P, Degrell P, Vannay A, Szabo AJ, Fekete A (2017) sigmal-receptor Agonism protects against renal ischemia-reperfusion injury. J Am Soc Nephrol 28(1):152-165. https://doi.org/10.1681/asn.2015070772

59. Cantow K, Flemming B, Ladwig-Wiegard M, Persson PB, Seeliger E (2017) Low dose nitrite improves reoxygenation following renal ischemia in rats. Sci Rep 7(1):14597-15058

60. Pohlmann A, Cantow K, Huelnhagen T, Grosenick D, Dos Santos PJ, Boehmert L, Gladytz $\mathrm{T}$, Waiczies $\mathrm{S}$, Flemming $\mathrm{B}$, Seeliger E, Niendorf T (2017) Experimental MRI monitoring of renal blood volume 
fraction variations En route to renal magnetic resonance oximetry. Tomography 3 (4):188-200. https://doi.org/10.18383/j. tom.2017.00012

61. Kumar P (2009) Systemic effects resulting from carotid body stimulation-invited article. Adv Exp Med Biol 648:223-233. https://doi. org/10.1007/978-90-481-2259-2_26

62. Lahiri S, Forster RE 2nd (2003) $\mathrm{CO}_{2} / \mathrm{H}(+)$ sensing: peripheral and central chemoreception. Int $\mathrm{J}$ Biochem Cell Biol 35 (10):1413-1435

63. Catchlove SJ, Pipingas A, Hughes ME, Macpherson H (2018) Magnetic resonance imaging for assessment of cerebrovascular reactivity and its relationship to cognition: a systematic review. BMC Neurosci 19(1):21. https://doi. org/10.1186/s12868-018-0421-4

64. Corfield DR, McKay LC (2016) Regional cerebrovascular responses to hypercapnia and hypoxia. Adv Exp Med Biol 903:157-167. https://doi.org/10.1007/978-1-4899-76789_11

65. Brezis M, Agmon Y, Epstein FH (1994) Determinants of intrarenal oxygenation. I. Effects of diuretics. Am J Physiol 267(6 Pt 2): F1059-F1062. https://doi.org/10.1152/ ajprenal.1994.267.6.F1059

66. Warner L, Glockner JF, Woollard J, Textor SC, Romero JC, Lerman LO (2011) Determinations of renal cortical and medullary oxygenation using blood oxygen level-dependent magnetic resonance imaging and selective diuretics. Investig Radiol 46(1):41-47. https://doi.org/10.1097/RLI. 0b013e3181f0213f

67. Prasad PV, Edelman RR, Epstein FH (1996) Noninvasive evaluation of intrarenal oxygenation with BOLD MRI. Circulation 94
(12):3271-3275. https://doi.org/10.1161/ 01.cir.94.12.3271

68. Palmucci S, Mammino L, Caltabiano DC, Costanzo V, Foti PV, Mauro LA, Farina R, Profitta ME, Sinagra N, Ettorre GC, Veroux M, Basile A (2019) Diffusion-MR in kidney transplant recipients: is diuretic stimulation a useful diagnostic tool for improving differentiation between functioning and non-functioning kidneys? Clin Imaging 53:97-104. https://doi.org/10.1016/j. clinimag.2018.10.003

69. Haddock B, Larsson HBW, Francis S, Andersen UB (2019) Human renal response to furosemide: simultaneous oxygenation and perfusion measurements in cortex and medulla. Acta Physiol (Oxf) 227:el3292. https://doi. org/10.1111/apha.13292

70. Welch WJ (2002) Adenosine Al receptor antagonists in the kidney: effects in fluidretaining disorders. Curr Opin Pharmacol 2 (2): 165-170

71. Gili S, Barbero U, Errigo D, De Luca G, Biondi-Zoccai G, Leone AM, Iannaccone $M$, Montefusco A, Omede P, Moretti C, D'Amico M, Gaita F, D'Ascenzo F (2018) Intracoronary versus intravenous adenosine to assess fractional flow reserve: a systematic review and meta-analysis. J Cardiovasc Med (Hagerstown) 19(6):274-283. https://doi. org/10.2459/jcm.0000000000000652

72. Solerno R, Pedroni P, Mariani J, Sarmiento R (2018) Comparison of sodium nitroprusside and adenosine for fractional flow reserve assessment: a systematic review and meta-analysis. Expert Rev Cardiovasc Ther 16(10):765-770. https://doi.org/10.1080/14779072.2018. 1513789

Open Access This chapter is licensed under the terms of the Creative Commons Attribution 4.0 International License (http://creativecommons.org/licenses/by/4.0/), which permits use, sharing, adaptation, distribution and reproduction in any medium or format, as long as you give appropriate credit to the original author(s) and the source, provide a link to the Creative Commons license and indicate if changes were made.

The images or other third party material in this chapter are included in the chapter's Creative Commons license, unless indicated otherwise in a credit line to the material. If material is not included in the chapter's Creative Commons license and your intended use is not permitted by statutory regulation or exceeds the permitted use, you will need to obtain permission directly from the copyright holder. 